Absorption and Fluorescence Features of an Amphiphilic meso-Pyrimidinylcorrole: Experimental Study and Quantum Chemical Calculations Peer-reviewed author version

Preiss, Julia; Herrmann-Westendorf, Felix; Ngo, Thien H.; Martinez, Todd; Dietzek, Benjamin; Hill, Jonathan P.; Ariga, Katsuhiko; Kruk, Mikalai M.; MAES, Wouter \& Presselt, Martin (2017) Absorption and Fluorescence Features of an Amphiphilic meso-Pyrimidinylcorrole: Experimental Study and Quantum Chemical Calculations. In: JOURNAL OF PHYSICAL CHEMISTRY A, 121(45), p. 8614-8624.

DOI: $10.1021 /$ acs.jpca.7b08910

Handle: http://hdl.handle.net/1942/25558 


\section{Absorption and Fluorescence Features of an Amphiphilic meso- \\ Pyrimidinylcorrole: Experimental Study and Quantum Chemical Calculations}

Julia Prei $\aleph^{1,2}$, Felix Herrmann-Westendorf ${ }^{1,2}$, Thien H. Ngo ${ }^{3,4}$, Todd Martínez ${ }^{5,6}$, Benjamin Dietzek $^{1,2,7}$, Jonathan P. Hill ${ }^{4}$, Katsuhiko Ariga ${ }^{4}$, Mikalai M. Kruk ${ }^{8}$, Wouter Maes ${ }^{9}$, Martin Presselt $1,2,7,10^{*}$

${ }^{1}$ Institute of Physical Chemistry, Friedrich Schiller University Jena, Helmholtzweg 4, 07743 Jena, Germany

${ }^{2}$ Leibniz Institute of Photonic Technology (IPHT), Albert-Einstein-Str. 9, 07745 Jena, Germany

${ }^{3}$ International Center for Young Scientists (ICYS), National Institute for Materials Science, Namiki 1-1, Tsukuba, Ibaraki 305-0044, Japan

${ }^{4}$ WPI Center for Materials Nanoarchitectonics, National Institute for Materials Science, Namiki 1-1, Tsukuba, Ibaraki 305-0044, Japan

${ }^{5}$ SLAC National Accelerator Laboratory, Menlo Park, California 94309, USA

${ }^{6}$ Department of Chemistry and PULSE Institute, Stanford University, Stanford, California 94305, USA

${ }^{7}$ Center for Energy and Environmental Chemistry Jena (CEEC Jena), 07743 Jena, Germany

${ }^{8}$ Belarusian State Technological University, Physics Department, Sverdlova str. 13a, Minsk 220006, Belarus

${ }^{9}$ UHasselt - Hasselt University, Institute for Materials Research (IMO-IMOMEC), Design \& Synthesis of Organic Semiconductors (DSOS), Agoralaan, 3590 Diepenbeek, Belgium

${ }^{10}$ Sciclus GmbH Co. KG, Moritz-von-Rohr-Str. 1a, 07745 Jena, Germany

*Corresponding author: e-mail: martin.presselt@leibniz-ipht.de, phone: +49 3641948356 


\section{ABSTRACT}

Corroles are emerging as an important class of macrocycles with numerous applications because of their peculiar photophysical and metal chelating properties. Meso-pyrimidinylcorroles are easily deprotonated in certain solvents, which changes their absorption and emission spectra as well as their accessible supramolecular structures. To enable control over the formation of supramolecular structures, the dominant corrole species, i.e. the deprotonated form or one of the two NH-tautomers, needs to be identified. Therefore, we focus in the present article on the determination of the UV-vis spectroscopic properties of the free-base NH-tautomers and the deprotonated form of a new amphiphilic meso-pyrimidinylcorrole that can assemble to supramolecular structures at hetero-interfaces as utilized in the Langmuir-Blodgett and liquidliquid interface precipitation techniques. After quantification of the polarities of the free-base $\mathrm{NH}$-tautomers and the deprotonated form by means of quantum chemically derived electrostatic potential distributions at the corroles' van der Waals surfaces, the preferential stabilization of (some of) the considered species in solvents of different polarity is identified by means of absorption spectroscopy. For the solutions with complex mixtures of species, we applied fluorescence excitation spectroscopy to estimate the relative weights of the individual corrole species. This technique might also be applied to identify dominating species in molecularly thin films directly on the subphase' surface of Langmuir-Blodgett troughs. Supported by quantum chemical calculations we were able to differentiate between the spectral signatures of the individual $\mathrm{NH}$-tautomers by means of fluorescence excitation spectroscopy. 


\section{INTRODUCTION}

The versatile photophysical properties ${ }^{1-3}$ and chelating abilities of corroles render this class of molecules of high interest for numerous applications $s^{4-5}$, such as novel catalysts ${ }^{6-9}$, antitumor and imaging agents ${ }^{10-12}$, molecular sensors ${ }^{13-17}$ and optoelectronic devices ${ }^{18-20}$. Corroles are macrocycles that, similar to porphyrins, contain four pyrrole rings ${ }^{21}$. In contrast to porphyrins, however, corroles contain only three meso-carbon atoms $\left(\mathrm{C}_{\mathrm{m}}\right)$ and one direct pyrrole-pyrrole $\left(\mathrm{C}_{\alpha}-\mathrm{C}_{\alpha}\right)$ linkage, as shown in Figure 1 . Moreover, corroles exhibit $\mathrm{NH}$-tautomerisation ${ }^{22}$, the possibility of a single protonation, and in principle three successive deprotonations ${ }^{23}$. Since the corrole NH-tautomers can differ significantly in their chemical and spectroscopic properties ${ }^{24-27}$, it is of interest to determine which one of the NH-tautomers dominates. Moreover, the chemical and spectroscopic properties of the deprotonated species differ even more from those of the aforementioned free-base $\mathrm{NH}$-tautomers. ${ }^{23}$

Since the spectroscopic and chemical properties of the abovementioned corrole species differ, the formation and properties of supramolecular structures and thin films will strongly depend on the corrole species that dominates during processing. Therefore, it is important to determine and control the protonation state and, when indicated, the dominant $\mathrm{NH}$-tautomer in stock solutions and during processing to yield supramolecular structures and thin films with the required properties.

In the present work, we have synthesized a new corrole that shows amphiphilicity, thus allowing its assembly into supramolecular structures, particularly at hetero-interfaces as utilized in the Langmuir-Blodgett $(\mathrm{LB})^{16,}{ }^{28-33}$ and liquid-liquid interface precipitation ${ }^{34-35}$ techniques (cf. porphyrinoids). In both, the LB and the LLIP techniques, polar solvents are involved. However, it 
was found that corroles show solvent dependent deprotonation, to which the polarity seems to have a key contribution. ${ }^{23}$ Hence, it is important to investigate the dependence of deprotonation and $\mathrm{NH}$-tautomerization on solvent properties, such as polarity, before performing extensive LB studies.

To utilize the UV-vis spectroscopic differences between the $\mathrm{NH}$-tautomers and the deprotonated form for identifying these individual species in different media, we have comprehensively analyzed their polarities and systematically resolved their individual UV-vis spectroscopic features. This spectroscopic characterization was performed experimentally and theoretically by measuring UV-vis absorption spectra and by analyzing fluorescence and fluorescence excitation spectra. The fluorescence-based techniques can be applied to determine the protonation or $\mathrm{NH}$-tautomerization state, for example in stock solutions and directly on the LB-trough surface in subsequent studies.

\section{METHODS}

\section{Synthetic Procedure}

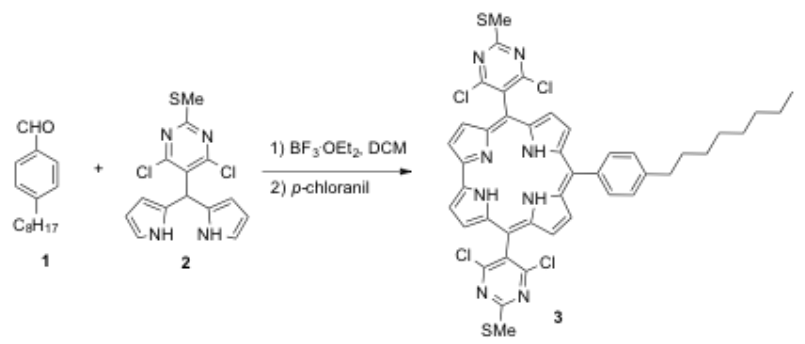

Scheme 1: Synthesis of the amphiphilic Pyrim ${ }_{2} \mathrm{Ph}_{1}$ Corrole.

The amphiphilic $A_{2} B$-pyrimidinylcorrole (Scheme 1) was synthesized under pseudo high-dilution conditions employing 0.043 equivalents of $\mathrm{BF}_{3} \cdot \mathrm{OEt}_{2}$ as Lewis acid catalyst. Synthetic strategies from the literature were used. ${ }^{36-40}$ 
A mixture of $p$-octylbenzaldehyde (1) and $\mathrm{BF}_{3} \cdot \mathrm{OEt}_{2}(3 \mu \mathrm{L}, 0.043$ equiv) in dichloromethane (50 $\mathrm{mL}$ ) was added dropwise over $2 \mathrm{~h}$ to a stirred solution of pyrimidinyldipyrromethane 2 (600 $\mathrm{mg}$, $1,17 \mathrm{mmol})$ in dichloromethane $(400 \mathrm{~mL})$, under $\mathrm{N}_{2}$. The mixture was shielded from light and further stirred overnight at room temperature. $p$-Chloranil $(200 \mathrm{mg}, 0.813 \mathrm{mmol}$ ) was then added and the mixture was refluxed for $1 \mathrm{~h}$. The solvent was evaporated under reduced pressure until $100 \mathrm{~mL}$ remained. The crude mixture was then first passed through a silica gel plug (in dichloromethane). Further purification was carried out by column chromatography (silica gel, dichloromethane:hexane 1:1) to give pure corrole 3 as a purple-green solid $(9.2 \mathrm{mg}$, 2\%). ${ }^{1} \mathrm{H} \mathrm{NMR}\left(300 \mathrm{MHz}, \mathrm{CDCl}_{3}, 25^{\circ} \mathrm{C}, \mathrm{TMS}\right): \delta=9.06\left(\mathrm{~d},{ }^{3} \mathrm{~J}(\mathrm{H}, \mathrm{H})=4.2 \mathrm{~Hz}, 2 \mathrm{H}, \mathrm{H}_{\beta}\right), 8.70\left(\mathrm{~d},{ }^{3} \mathrm{~J}(\mathrm{H}, \mathrm{H})=\right.$ $\left.4.8 \mathrm{~Hz}, 2 \mathrm{H}, \mathrm{H}_{\beta}\right), 8.61\left(\mathrm{~d},{ }^{3} \mathrm{~J}(\mathrm{H}, \mathrm{H})=4.8 \mathrm{~Hz}, 2 \mathrm{H}, \mathrm{H}_{\beta}\right), 8.51\left(\mathrm{~d},{ }^{3} \mathrm{~J}(\mathrm{H}, \mathrm{H})=4.2 \mathrm{~Hz}, 2 \mathrm{H}, \mathrm{H}_{\beta}\right), 8.08\left(\mathrm{~d},{ }^{3}(\mathrm{H}, \mathrm{H})\right.$ $\left.=7.9 \mathrm{~Hz}, 2 \mathrm{H}, \mathrm{H}_{\mathrm{ar}}\right), 7.56\left(\mathrm{~d},{ }^{3}(\mathrm{H}, \mathrm{H})=7.9 \mathrm{~Hz}, 2 \mathrm{H}, \mathrm{H}_{\mathrm{ar}}\right), 2.95-2.90(\mathrm{~m}, 2 \mathrm{H}), 2.84\left(\mathrm{~s}, 6 \mathrm{H}, \mathrm{H}_{\mathrm{sme}}\right)$, $1.95-1.85(\mathrm{~m}, 2 \mathrm{H}), 1.56-1.41(\mathrm{~m}, 8 \mathrm{H}), 0.96-0.83(\mathrm{~m}, 5 \mathrm{H}),-2.35(\mathrm{sbr}, 3 \mathrm{H}, \mathrm{NH}) \mathrm{ppm} .{ }^{13} \mathrm{C}$ NMR $(75$ $\left.\mathrm{MHz}, \mathrm{CDCl}_{3}, 25^{\circ} \mathrm{C}, \mathrm{TMS}\right): \delta 173.5,163.4,142.5,138.4,134.5(\mathrm{CH}), 128.1(\mathrm{CH}), 127.4(\mathrm{CH}), 125.9$, 125.0 (CH), 117.2 (CH), 77.2 (CH), 36.0 $\left(\mathrm{CH}_{2}\right), 32.0 / 31.7\left(\mathrm{CH}_{2}\right), 29.7 / 29.6 / 29.4\left(\mathrm{CH}_{2}\right), 22.8\left(\mathrm{CH}_{2}\right)$, $14.8\left(\mathrm{CH}_{3}\right), 14.2\left(\mathrm{CH}_{3}\right)$ ppm. MALDI-TOF: calc. $872.14\left[\mathrm{M}^{+}\right]$; found 872.27 .

\section{Experimental Details}

Absorption spectra were recorded with a Varian Cary 5000 spectrometer. Overview emission and fluorescence excitation spectra were measured with a spectrofluorometer LS50B from Perkin Elmer. Detailed emission spectra at different excitation wavelengths were recorded with an in-house setup. This setup uses a Princeton Instruments Isoplane 320 spectrograph with a Pixis 400 eXelon CCD camera to measure even very small fluorescence intensities. A $1200 \mathrm{l} / \mathrm{mm}$ grating with a blaze wavelength of $500 \mathrm{~nm}$ was used and the slit was set to $500 \mu \mathrm{m}$, resulting in 
a spectral resolution of $1.7 \mathrm{~nm}$. All measurements were corrected for the setup's response curve. We used a $450 \mathrm{~W}$ Xe lamp and a monochromator with a focal length of $260 \mathrm{~mm}$ (LOTQuantum Design) as a monochromatic light source for excitation. The monochromator's slits were set to $2 \mathrm{~mm}$, giving a spectral resolution of $7 \mathrm{~nm}$.

\section{Quantum Chemical Details}

All quantum chemical results were obtained with the functional $\omega \mathrm{PBEh}^{41}$ and the basis set $\operatorname{lan} 12 \mathrm{dz}^{42}$. We employed an $\omega$ of $0.12 / \mathrm{a}_{\mathrm{B}}$, which we obtained using omega-tuning ${ }^{43-45}$ as implemented in an in-house code ${ }^{46}$. The omega is tuned so that Koopmans' theorem is obeyed as closely as possible, therefore enforcing optimized HOMO and LUMO energy. However, it has been shown, that also a good description of the low lying excited states can be achieved in cases where the orbitals involved have a similar character as HOMO and LUMO ${ }^{47-48}$ The omega-tuning was done without solvent model. Results obtained at the ground state geometries of T1 and T2 both resulted in the same optimal omega value, which was then used for all further calculations. Vibrational analysis of the ground state geometries was done to check that true minima were found during the optimization. All calculations were done with a development version of TeraChem ${ }^{49}$.

Vibrationally broadened absorption spectra were calculated with the nuclear ensemble method $^{50-51}$ by sampling 585 geometries per tautomer using ab initio molecular dynamics (AIMD) and a Langevin thermostat as suggested by Isborn et al. ${ }^{52}$. The AIMD was conducted with a time step of $1.5 \mathrm{fs}$. After an equilibration time of $20 \mathrm{ps}$, geometries were sampled every $500 \mathrm{fs}$. Independence of the samples was tested based on the autocorrelation function used by Isborn et al. ${ }^{52}$. All individual electronic transitions of the different geometries were broadened 
with Gaussian functions of a full width at half maximum of $0.03 \mathrm{eV}$ before being added up, resulting in a smooth total spectrum. To decrease the computational effort, AIMD and subsequent TDDFT calculations were done with a shorter R2 moiety, consisting of phenyl- $\mathrm{C}_{3} \mathrm{H}_{7}$. This is a valid approximation as the normal modes and the electronic excitations of the Q-band region are not significantly influenced by the length of the alkyl chain.

The discretized vdW surfaces were obtained using the skin-surface model as implemented in the Computational Geometry Algorithms Library $(\mathrm{CGAL})^{53}$. The electrostatic potential at these points was computed from the quantum mechanical orbitals according to the well-known expression

$$
V(\mathbf{r})=\sum_{i=1}^{N} \frac{Z_{i}}{\left|\mathbf{r}-\mathbf{R}_{i}\right|}-\sum_{\mu=1}^{M} \sum_{v=1}^{M} P_{\mu v} \int_{\mathfrak{R}^{3}} \frac{\chi_{\mu}\left(\mathbf{r}^{\prime}\right) \chi_{\nu}\left(\mathbf{r}^{\prime}\right)}{\left|\mathbf{r}-\mathbf{r}^{\prime}\right|} d \mathbf{r}^{\prime}
$$

using an altered version of the numerical integrator for the local part found in the literature ${ }^{54}$ with spherical harmonics computed using the Boost library ${ }^{55}$. Here, $\mathrm{P}$ is the first order density matrix, the $\chi$ are the contracted Gaussian basis functions and $Z$ is the nuclear charge. All capital letters correspond to the nuclei. The data was organized using a Python program and interfaces to parts written in other programming languages which were generated using the Simplified Wrapper Interface Generator (SWIG) ${ }^{56}$. The figures were rendered using the Persistence of Vision Raytracer (PoVRay) version 3.7.1 ${ }^{57}$ 


\section{RESULTS AND DISCUSSION}

\section{Polarity of the Different Corrole Species}

To enable (self)assembly at hetero-interfaces for extending supramolecular structures, we induced amphiphilicity to a specific meso-pyrimidinylcorrole. Therefore, 4,6-dichloro-2methylsulfanylpyrimidinyl groups (Pyrim) were inserted in the 5- and 15-positions to increase the hydrophilicity of the molecule, while a p-octylphenylene group (Ph) was placed in the 10position to act as the lipophilic moiety (total abbrev. Pyrim ${ }_{2} \mathrm{Ph}_{1}$ Corrole), as shown in Figure 1. For details on the synthesis, see methods section.

The amphiphilic character is visualized by the quantum mechanically calculated electrostatic potential distribution $\varphi(r)$ derived from the electron density distribution ${ }^{58-60}$ at the van der Waals (vdW) surface (for computational details, see methods section) in Figure 1. From electrostatic potential and charge distributions on vdW surfaces, solubilities as well as reactivities can be estimated ${ }^{61-63}$, cf. the seminal work of Klamt et al. on the analysis of screening counter charges in conductor environments. ${ }^{62,64-65}$ As shown in Figure 1, the freebase macrocycle features high absolute $\varphi$-values, while the alkyl moiety has a rather noncharged van der Waals surface, thus indicating amphiphilicity. Furthermore, the calculated dipole moments show large differences between the free-base NH-tautomers T1 (3.1 D) and T2 (1.8 D).

To understand the rather large difference between the NH-tautomer's dipole moments, the chemical difference between the NH-tautomers was considered. Since NH-tautomerization occurs essentially at the corrole core, similar dipole moment differences between the $\mathrm{NH}$ tautomers (structures in Figure 1 (Pyrim ${ }_{2} \mathrm{Ph}_{1}$ Corrole): $\left.\Delta \mathrm{p}(\mathrm{T} 1, \mathrm{~T} 2)=1.34 \mathrm{D}\right)$ would also be 
expected for already reported corrole derivatives. However, a comparison with unsubstituted corrole reveals the significant influence of the meso-substituents on $\Delta p(T 1, T 2)$, which is 2.4 times higher for Pyrim $\mathrm{Ph}_{1}$ Corrole than for the pristine corrole, as shown in Table 1.

This large increase in $\Delta p(T 1, T 2)$ upon meso-substitution is related to the strong increase in the individual tautomers' dipole moments due to the negative $\varphi$-values at the phenylene groups, as shown in Figure 1. The increased negative $\varphi$-values at the $R_{2}$ substituent, in combination with the partially positively charged corrole core, cause the orientation of the resulting dipole to be similar to the direction of tautomerization, i.e. the orientation of a vector defined by the nitrogen atoms involved in tautomerization, $\mathrm{N}(23)$ and $\mathrm{N}(24)$, see Table 1 for the angels. However, upon tautomerization from T1 to T2 the charge distribution in the core naturally changes, as shown in Figure 1, and shrinks and tilts the dipole away from the tautomerization direction (angles listed in Table 1). In case of the recently published Mes ${ }_{2}$ Pyrim $_{1}$ Corrole $^{26}$ (see SI Figure S1 for molecular structure) the change in magnitude and angle of the dipole upon tautomerization is smaller than in case of the here-investigated $\mathrm{Pyrim}_{2} \mathrm{Ph}_{1}$ Corrole, see Table 1.

Besides tautomerization, it was shown that in the case of the meso-mesityl (Mes) derivative Mes $_{2}$ Pyrim ${ }_{1}$ Corrole, deprotonation occurs in certain solvents. ${ }^{23}$ This solvent-dependence of the deprotonation arises from different solvent screening of surface charges, as shown in Figure 1, of the deprotonated species. ${ }^{65}$ Thus, in addition to molecular properties like electron delocalization and polarizability, the charge screening by a solvent heavily influences the chemical potential and finally the $\mathrm{pK}_{\mathrm{B}}$ in solution, as recently shown for porphyrins ${ }^{62}$. This charge screening is improved with increasing solvent permittivity, albeit other solvent 
properties, like dipole-moment, proticity and more are known to influence acid-base equilibria and were combined to various descriptors to better account for specific solvatochromic effects, cf. the work of $\operatorname{Taft}^{66}{ }^{6}$, Hammett $^{67}$, Swain ${ }^{68}$, and others ${ }^{69}$. In a rough approximation, we might consider the molecular dipole moment as a descriptor of the charge distribution to facilitate the discussion in the following section. Within this approximation, we ascribe the more facile deprotonation with increasing solvent permittivity to molecules with larger differences between the dipole moments of the acidic and the deprotonated form as compared to molecules with smaller dipole moment differences. Following this approximation, the dipole moments of the free-base $\mathrm{NH}$-tautomers and those of the deprotonated forms of Mes 2 Pyrim ${ }_{1}$ Corrole, Pyrim ${ }_{2} \mathrm{Ph}_{1}$ Corrole (introduced here), and the corrole reference compound are compared in Table 1 to investigate how solvent permittivity might influence deprotonation.

The deprotonated species of Mes ${ }_{2}$ Pyrim $_{1}$ Corrole and the pristine corrole have very small dipole moments $(p<1 D)$, well below the respective dipole moments of T1 and T2. In contrast to this, the deprotonated species of the corrole studied here has a much larger dipole moment (9.25 D) than the free-base tautomers, which is induced by negative charge accumulating mainly at the corrole core, while the alkyl chain is neutral. As the difference in dipole moments between the deprotonated Pyrim ${ }_{2} \mathrm{Ph}_{1}$ Corrole and its T1-tautomer is about four times greater than $\Delta \mathrm{p}(\mathrm{T} 1, \mathrm{~T} 2)$, deprotonation is increasingly probable with larger solvent dipolarity as compared to accumulation of the more polar NH-tautomer (T1). Thus, systematic variation of the solvent dipolarity (same order if sorted for permittivity within the small set of solvents employed here) appears to be a suitable approach for identification of the individual spectral features of $\mathrm{NH}$ tautomers and the deprotonated Pyrim ${ }_{2} \mathrm{Ph}_{1}$ Corrole, as discussed in the following section. 
Table 1: Dipole moments $p$ of different species of the three corroles studied as well as angle between the tautomerization direction and the dipole moment and the differences between the dipole moments of the different species. We calculated all dipole moments listed here (for the new amphiphilic $\mathrm{Pyrim}_{2} \mathrm{Ph}_{1}$ Corrole as well as for the two reference corroles) by means of TDDFT at the $\omega$ PBEh/lanl2dz level of theory using a range-separation parameter of $\omega=0.12 / a_{B}$. For comparability of all calculation, the omega obtained using the omega-tuning for the Pyrim ${ }_{2} \mathrm{Ph}_{1}$ Corrole was applied for all three corroles (for further details see methods section).

\begin{tabular}{|c|c|c|c|}
\hline & Corrole & Mes $_{2}$ Pyrim $_{1}$ Corrole & Pyrim $_{2} \mathrm{Ph}_{1}$ Corrole \\
\hline |p(deprotonated)| [D] & 0.62 & 0.71 & 9.25 \\
\hline$|p(T 1)|[D]$ & 1.74 & 3.76 & 3.10 \\
\hline$|p(T 2)|[D]$ & 1.18 & 2.54 & 1.76 \\
\hline$\Varangle(p($ deprotonated), $\overrightarrow{\mathrm{N}(23) \mathrm{N}(24))}$ & $1.91^{\circ}$ & $5.67^{\circ}$ & $9.23^{\circ}$ \\
\hline$\Varangle(p(T 1), \overrightarrow{N(23) N(24)})$ & $47.46^{\circ}$ & $21.75^{\circ}$ & $31.62^{\circ}$ \\
\hline$\Varangle(p(T 2), \overrightarrow{N(23) N(24))}$ & $77.00^{\circ}$ & $32.83^{\circ}$ & $51.65^{\circ}$ \\
\hline$\Delta p(T 1, T 2)=|p(T 1)|-|p(T 2)|[D]$ & 0.56 & 1.22 & 1.34 \\
\hline $\mid p($ deprotonated) $|-| p(T 1) \mid[D]$ & 1.12 & 3.05 & 6.15 \\
\hline $\mid p($ deprotonated) $|-| p(T 2) \mid[D]$ & 0.56 & 1.83 & 7.49 \\
\hline
\end{tabular}




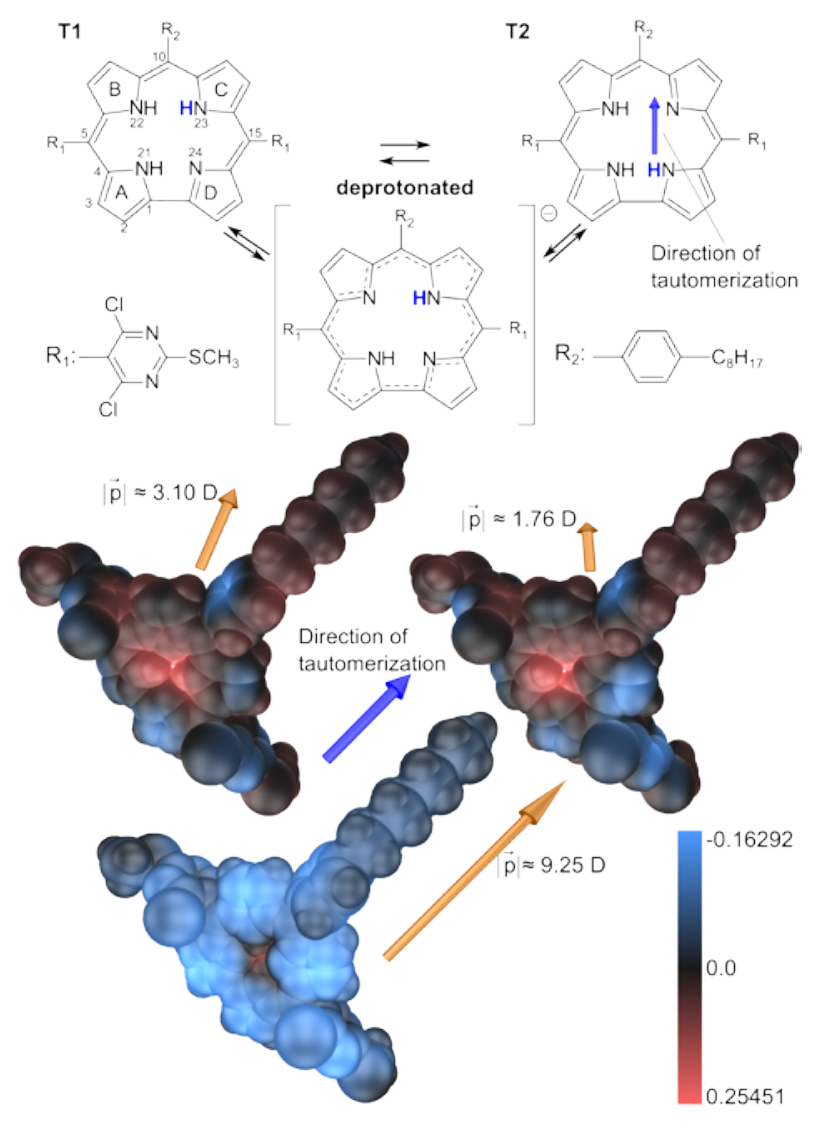

Figure 1: Lewis structures of the two NH-tautomers and the deprotonated species of the amphiphilic pyrimidinylcorrole. Orange arrows indicate the calculated dipole moments and blue arrows indicate the direction of tautomerization. The plots of the electrostatic potential distribution at the Van der Waals surface are shown to visualize amphiphilicity. Red, blue and black correspond to a positive, negative and vanishing electrostatic potential, respectively. The saturation of the color is a direct measure of the strength of the electrostatic potential with independent red-black and blue-black color scales. The optimized vacuum geometries of T1, T2 and the deprotonated species on which the potential plots are based are given in Tables S2, S3 and S4 in the Supporting Information.

\section{Absorption Spectra in Solvents of Different Polarity}

In the absorption spectra measured in different solvents, shown in Figure 2a, four distinct absorption bands can be observed in the Q-band spectral range at 1.94, 2.01, 2.15, and $2.38 \mathrm{eV}$, respectively. The spectra show only minor differences in a multitude of solvents with different 
basicity and permittivity, (according to Kamlet-Taft parameters ${ }^{70}$, see SI Table S2). This means that solvatochromic effects are negligible for individual corrole species in the solvents shown in Figure 2a. This very weak solvatochromism of the Q-band is corroborated by the very small differences between time-dependent density functional theory (TDDFT) derived absorption spectra of $\mathrm{T} 1$ and $\mathrm{T} 2$ in calculations employing solvent effects using a high dielectric constant $(\varepsilon($ propylene carbonate $)=64.0)$ and a low dielectric constant $(\varepsilon$ (chloroform $)=4.81)$, as shown in Figure $2 \mathrm{~b}$. The first two transitions for $\mathrm{T} 1$ and $\mathrm{T} 2$ are mainly of $\pi \rightarrow \pi^{*}$ character and are centered on the corrole core, see supporting information for details. Therefore, their calculated transitions energies are not as strongly influenced by the simulated solvent as the transition energies of the deprotonated species, which involves significant charge transfer character. The calculated peak positions of the $S_{0} \rightarrow S_{1}$ transitions for both tautomers match the experiment. In contrast to this, the relative intensities and the energies of the $S_{0} \rightarrow S_{2}$ transitions cannot be described as good by the calculations. This is probably due to the high influence of vibrational progression, as is often the case for porphyrins and corroles. ${ }^{25}$ The frontier orbitals of the three species and the nature of the corrole's Q-band transitions as visualized by means of charge difference densities ${ }^{71-73}$ are shown in Figure S2 to S4 as calculated without solvent. 


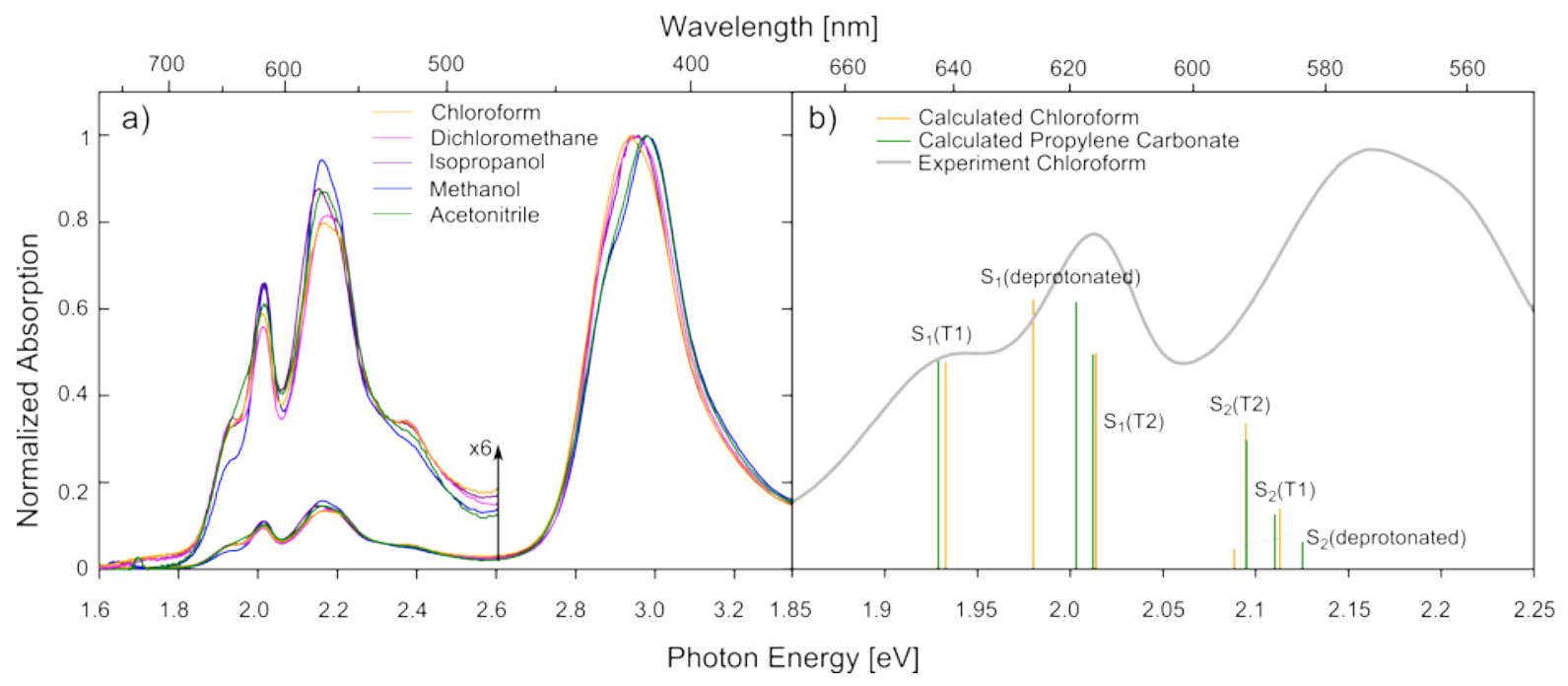

Figure 2: a) Normalized absorption spectra of the investigated amphiphilic $\mathrm{Pyrim}_{2} \mathrm{Ph}_{1}$ Corrole in various solvents (corrole concentration: $11.5 \mu \mathrm{mol} / \mathrm{ml}$ ). The Q-band spectral range is enlarged by a factor of six to provide a better view on the spectral changes in this region. b) Absorption spectra of the investigated amphiphilic corrole in chloroform. The calculated stick spectra of $\mathrm{T} 1, \mathrm{~T} 2$ and the deprotonated species are shown in orange and green for chloroform $(\varepsilon=4.81)$ and propylene carbonate $(\varepsilon=64.0)$, respectively. Sticks are shifted by $0.365 \mathrm{eV}$ and calculated at the $\omega P B E h /$ lanl2dz level of theory using a rangeseparation parameter of $\omega=0.12 / \mathrm{a}_{\mathrm{B}}$ and $\operatorname{COSMO}{ }^{64,74}$ to describe solvent effects.

However, dissolving the corrole in very dipolar propylene carbonate (Kamlet-Taft dipolarity $\pi^{*}=0.9$ ) leads to a new band at $1.96 \mathrm{eV}$ (see Figure 3a). Additionally, a peak at $2.10 \mathrm{eV}$ arises that lies beneath the shoulder of the $2.15 \mathrm{eV}$ peak in other solvents. Furthermore, an additional peak in the Soret-band appears at $\sim 2.80 \mathrm{eV}$ for the propylene carbonate solution. When mixing increasing amounts of propylene carbonate into a chloroform solution, the peaks at 1.96, 2.10 and $2.80 \mathrm{eV}$ systematically increase, whereas the peaks at 2.01 and $2.15 \mathrm{eV}$ that dominate the spectra measured in chloroform decrease. Because of the significant difference between the spectra measured in propylene carbonate and the other solvents, the exclusion of large specific solvatochromic effects, and the larger polarity of propylene carbonate, we conclude that in the 
propylene carbonate solution a different species is predominant. Even though propylene carbonate has a low basicity according to Kamlet-Taft hydrogen bond acceptor strength $\beta$, we assume that this species is the deprotonated corrole.

In order to verify this hypothesis, we added tetramethylguanidine (TMG) as an organic base to the chloroform solution. With increased TMG concentration, the same form of peaks as that observed for the propylene carbonate solution arises, as shown in Figure $3 \mathrm{~b}$. Because of the high basicity of TMG, we assign the spectral features that arise both with increasing TMG and propylene carbonate concentration to the deprotonated corrole. Therefore, we conclude that also in dipolar solution like in propylene carbonate or at a water-surface, e.g. on a LB trough (as outlined in the introduction), the corrole is deprotonated to a substantial extent. Thus, in case of the LB technique, the protonation state can be influenced by variation of the $\mathrm{pH}$ of the subphase upon processing and by the polarity in the thin film, which can be tuned by means of matrix molecules and additives.

The protonation state of the corrole in the molecularly thin Langmuir layer on the LB trough could possibly be identified by analyzing the Q-band spectral range. However, because of the weak absorption of the Langmuir layer, highly sensitive spectroscopic techniques such as fluorescence and fluorescence excitation spectroscopy might be applied to characterize Langmuir layers. Thus, in the following section, the fluorescence and fluorescence excitation spectra of the different Pyrim ${ }_{2} \mathrm{Ph}_{1}$ Corrole species are analyzed. 


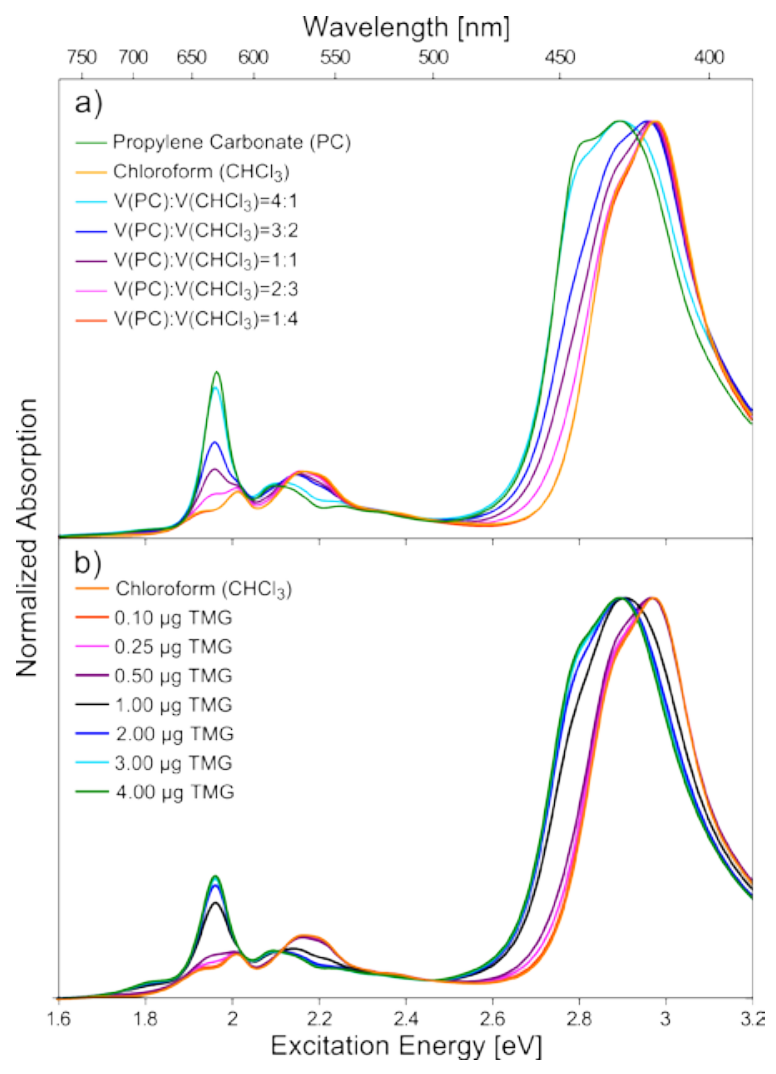

Figure 3: a) Normalized absorption spectra of the investigated amphiphilic $\mathrm{Pyrim}_{2} \mathrm{Ph}_{1}$ Corrole in chloroform and propylene carbonate and different mixtures of both solvents with ratios of volumes 4:1, 3:2, 1:1: 2:3 and 1:4(corrole concentration: $28.6 \mu \mathrm{mol} / \mathrm{l})$ b) Normalized absorption spectra of the investigated amphiphilic corrole in chloroform with increasing amounts of tetramethylguanidine (TMG). (corrole concentration: $4.6 \mu \mathrm{mol} / \mathrm{l}$ )

\section{Fluorescence and Fluorescence Excitation Spectra}

\section{Free-base and Deprotonated Corrole Species}

The fluorescence spectrum of the amphiphilic corrole in chloroform solution (see Figure 4) shows a pronounced maximum at $1.87 \mathrm{eV}$ with two shoulders at 1.98 and $1.74 \mathrm{eV}$. In contrast to this, the fluorescence spectrum in propylene carbonate has a blue-shifted maximum at $1.94 \mathrm{eV}$ and only one additional band at $1.76 \mathrm{eV}$. When mixing increasing amounts of propylene carbonate into the chloroform solution, the maximum first shifts very slowly towards that of the 
propylene carbonate solution because the quantum yield of the corrole in chloroform solution is higher than that in propylene carbonate ${ }^{1}$.

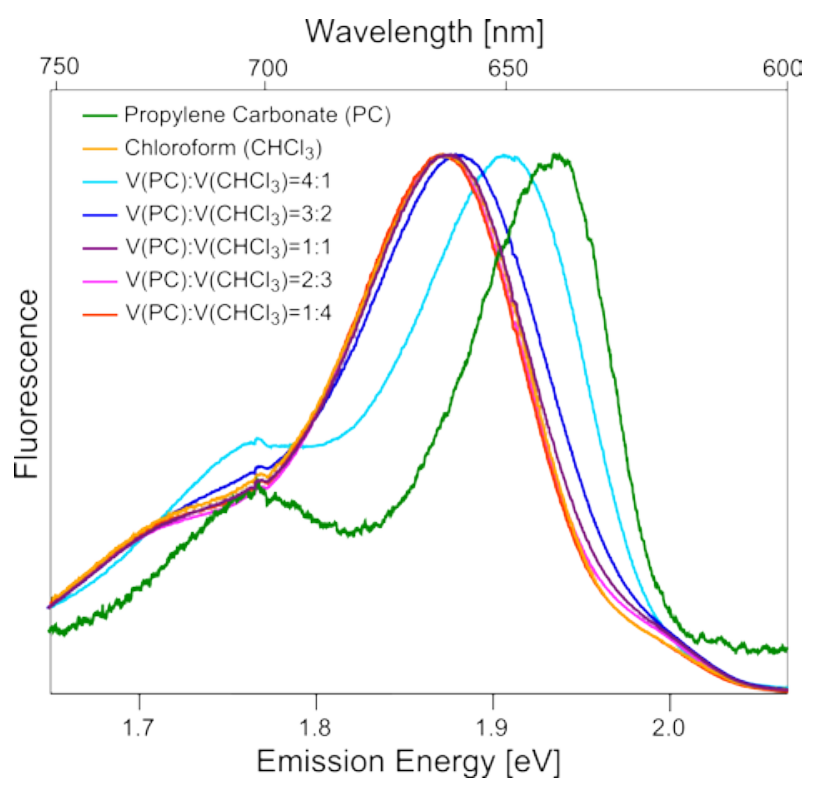

Figure 4: Normalized Fluorescence spectra of the investigated amphiphilic Pyrim ${ }_{2} \mathrm{Ph}_{1}$ Corrole in chloroform and propylene carbonate (corrole concentration: $1.15 \mu \mathrm{mol} / \mathrm{l}$ ) and five different mixtures of both solvents (corrole concentration: $13.75 \mu \mathrm{mol} / \mathrm{l})$.

After having characterized the basic absorption and fluorescence features of the deprotonated and the free-base corrole species based on preferential stabilization in solvents of different polarity, we investigated whether the abovementioned individual spectroscopic features can be identified in a more complicated solution containing an approximately balanced mixture of freebase and deprotonated species. Since their fluorescence spectra are significantly different,

\footnotetext{
${ }^{1}$ The relative quantum efficiency in propylene carbonate is $14 \%$ of that in chloroform. The quantum efficiency was calculated as the integral intensity of the fluorescence peak weighted by the absorbance at the excitation wavelength of $405 \mathrm{~nm}$.
} 
fluorescence excitation (FE) spectroscopy of a corrole solution with balanced volume fractions of propylene carbonate and chloroform was performed.

The energies of the fluorescence maxima of the pure propylene carbonate and chloroform solutions, 1.94 and $1.87 \mathrm{eV}$, respectively, would normally be used as detection energies for the FE-spectra. However, because of the different quantum yields in these solvents, the overall intensity of the fluorescence at $1.94 \mathrm{eV}$ is very weak in the solvent mixture. Therefore, FEspectra were detected at systematically scanned emission energies, as shown in Figure $5 \mathrm{a}$, to identify which emission energies yield the most different FE-spectra with acceptable signal to noise ratio. To facilitate the comparison, the FE-spectra were normalized to the FE-peak at $2.14 \mathrm{eV}$. Significant differences in the lower-energy FE-peak at around $1.96 \mathrm{eV}$ can be seen for the spectra detected at emission energies of 1.900 and $1.825 \mathrm{eV}$ (light blue and black, respectively, in Figure 5a). With increased detection energy, the intensity of the FE-peak at $1.96 \mathrm{eV}$ rises significantly compared to the normalization peak. From these significant differences, we conclude that different species can be extracted from these FE-spectra. This is visualized in more detail in Figure 5b, which shows the difference fluorescence (DF) intensity in relation to the fluorescence spectrum at an excitation energy of $2.14 \mathrm{eV}$ plotted over emission energies between 1.75 and $1.96 \mathrm{eV}$. The DF-spectra for excitation energies lower than the normalization peak exhibit a minimum at an emission energy of about $1.83 \mathrm{eV}$ and increase strongly in intensity for higher energies up to a maximum at $\sim 1.94 \mathrm{eV}$. In contrast to this, the DF-spectrum at an excitation energy of $2.19 \mathrm{eV}$ shows the opposite behavior, having a broad maximum between 1.80 and $1.85 \mathrm{eV}$. This leads to the conclusion that the DF-spectra for 
different excitation energies fall into two groups, which we assign to the free-base and the deprotonated species.

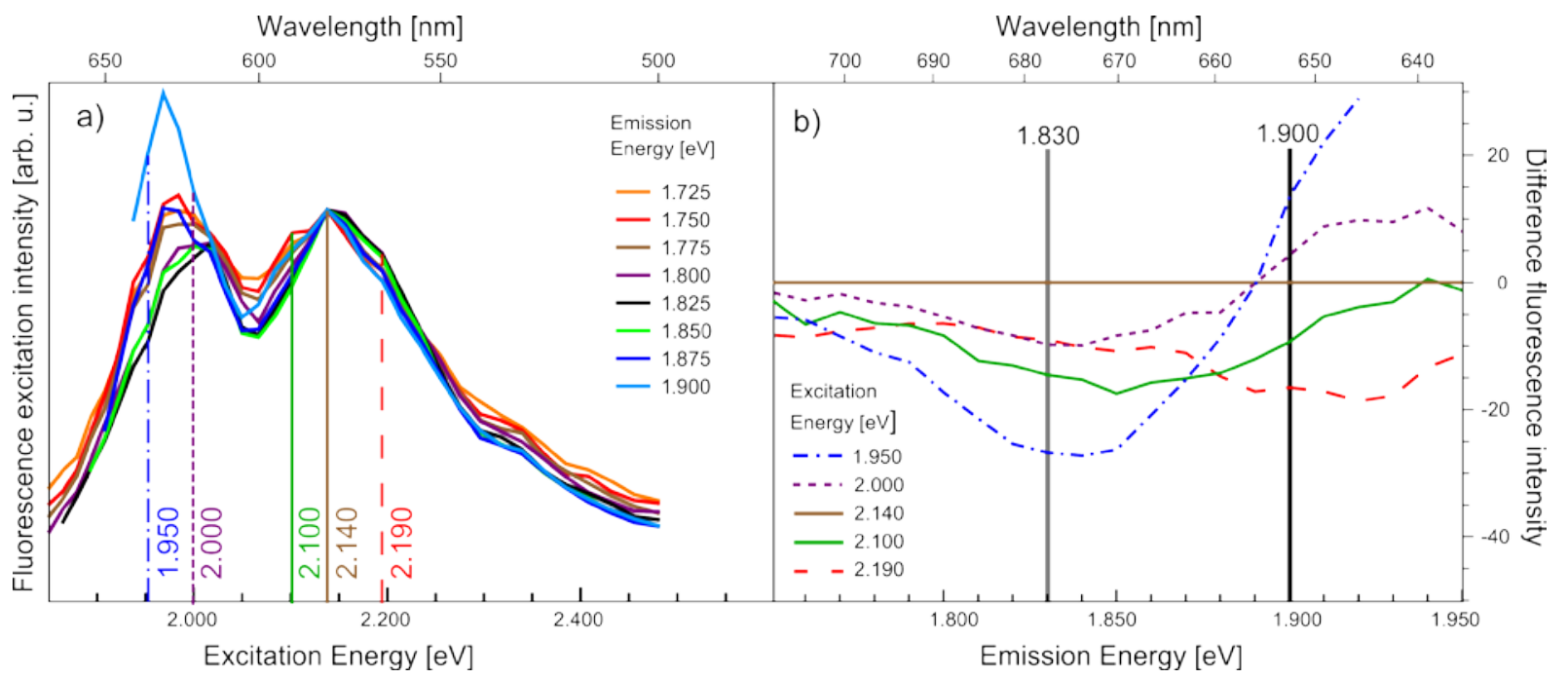

Figure 5: a) Normalized fluorescence excitation (FE, normalized at $2.14 \mathrm{eV}$, corrole concentration: $1.15 \mu \mathrm{mol} / \mathrm{l}$ in solution of balanced volume fractions of propylene carbonate and chloroform) spectra of $\mathrm{Pyrim}_{2} \mathrm{Ph}_{1}$ Corrole detected at systematically varied emission wavelengths (in the range from 1.725 to $1.900 \mathrm{eV}$ ). b) Difference fluorescence intensities for different excitation energies in relation to the fluorescence spectrum at an excitation energy of $2.14 \mathrm{eV}$ plotted over the emission wavelength.

From the analysis presented above, we conclude that FE-spectra taken at emission energies of 1.83 and $1.90 \mathrm{eV}^{2}$ (see vertical lines in grey and black, respectively, in Figure 5b) can be used to unambiguously deconvolute the overall absorption spectrum of a mixed solution of the deprotonated and free-base species into the spectra of the pure species. In order to obtain a first approximation of the ratio with which both species contribute to the FE-spectra at emission energies of 1.83 and $1.90 \mathrm{eV}$, we used the absorption spectra measured in pure propylene

\footnotetext{
${ }^{2}$ The overall intensity at $1.95 \mathrm{eV}$ is very low, so we used the FE-spectra at $1.90 \mathrm{eV}$ instead
} 
carbonate and chloroform as first approximations for the spectra of the pure deprotonated and free-base species, respectively. This is reasonable, as we previously concluded that these are each dominated by one of the two species, i.e. that they have spectral ratios of approx. 1/0 and $0 / 1$, respectively. The spectral ratios for the FE-spectra were estimated by simply fitting the absorption spectra of pure chloroform and propylene carbonate to each FE-spectrum in the one-to-one solvent mixture, as detailed in the Supporting Information. The resulting fits are shown in Figure $6 a$. This procedure results in a spectral ratio of $\sim 1 / 3(1 / 1)$ for the spectrum obtained at an emission energy of $1.83 \mathrm{eV}(1.90 \mathrm{eV})$.

Assuming that the overall FE-spectra are simply a linear combination of the absorption spectra of the pure species, we can use the previously obtained spectral ratios to approximate the linear combination coefficients. Using these coefficients and the FE-spectra at both emission energies (1.83 and $1.90 \mathrm{eV})$, two independent equations are obtained for each absorption wavelength, which can be used to solve for the intensity of the pure species at each absorption wavelength. Using this method, we obtain the whole spectrum for the deprotonated and the free-base species (see SI for a detailed explanation). The resulting spectra are shown in Figure $6 \mathrm{~b}$ for the deprotonated and the free-base species in orange and blue, respectively. This method can be used to obtain reasonable approximations for the spectra of different species and also to determine approximate spectral ratio. However, in the above described procedure we did not consider the free-base consisting of actually two NH-tautomers with slightly different spectroscopic properties, thus basically treating a spectral average of the NH-tautomers. In the following section we investigate whether the procedure described above can be used to differentiate even between the absorption spectra of the individual $\mathrm{NH}$-tautomers. 


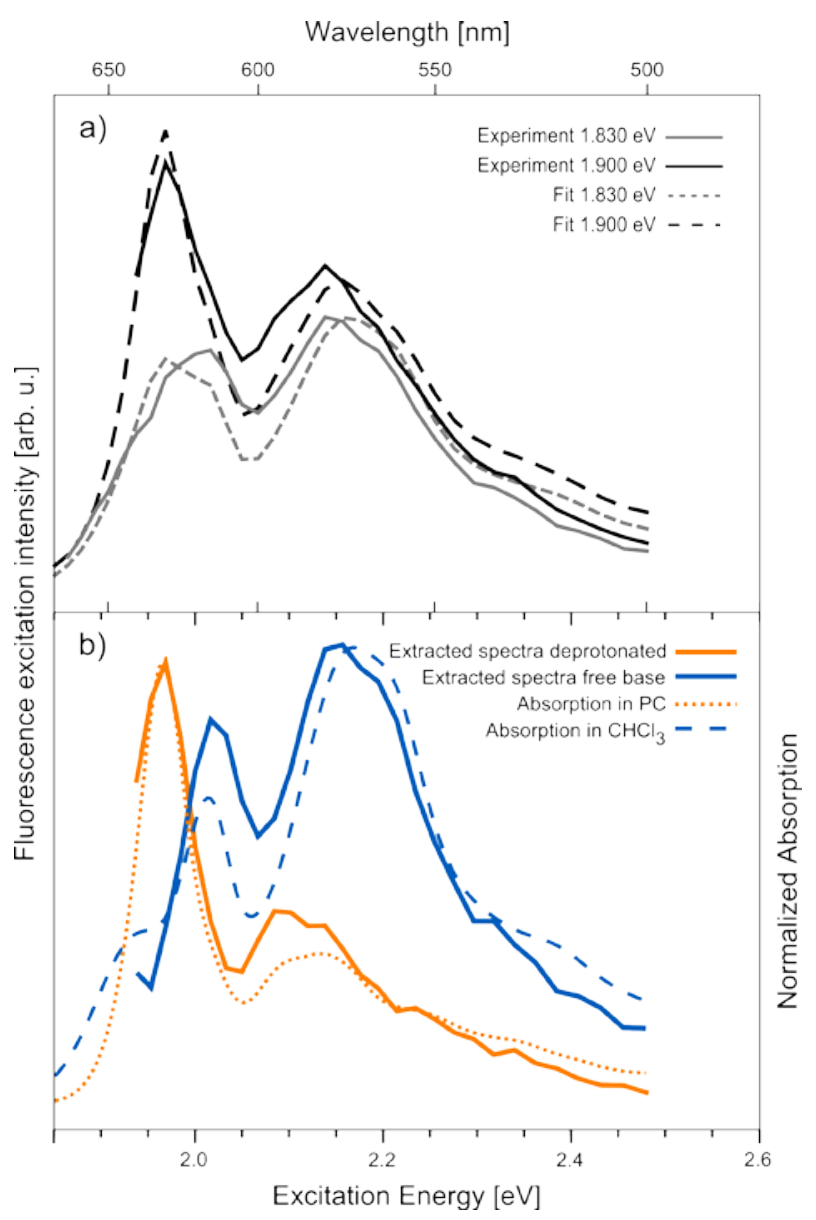

Figure 6: a) Dashed lines are the fit of the spectra in pure chloroform and propylene carbonate to the characteristic FE-spectra at emission energies of $1.830 \mathrm{eV}$ (solid gray) and $1.900 \mathrm{eV}$ (solid black). b) Extracted spectra of the deprotonated species (orange solid line) and the free-base species (dashed blue line) as obtained from the analysis of the FE-spectra in comparison to the absorption spectra in propylene carbonate (PC) and chloroform $\left(\mathrm{CHCl}_{3}\right)$ (dotted and dashed lines).

\section{NH-Tautomers}

In chloroform, no spectral features of the deprotonated species can be observed. Therefore, we chose the chloroform solution to investigate whether detection and analysis of the FE-spectra yields individual spectral features of the NH-tautomers. A comparison of the fluorescence and 
absorption spectra shows that the fluorescence peak at $1.98 \mathrm{eV}$ has a higher $\mathrm{S}_{1} \rightarrow \mathrm{S}_{0}$ transition energy than the lowest energy absorption peak at $1.94 \mathrm{eV}$. Thus, these peaks cannot belong to the same species. This leads us to the conclusion that the main fluorescence peak at $1.87 \mathrm{eV}$ can be assigned to the same chemical species as the lowest absorption peak. Therefore, different FE-spectra, originating from the absorption spectra of the respective species, should be obtained when detecting the emission at 1.98 and $1.87 \mathrm{eV}$.

Based on an analysis as described above, we identified the FE-spectra at 1.75 and $1.90 \mathrm{eV}$ as the ones with the most significant difference with acceptable signal to noise ratio, see Figure 7a. Even though the spectral ratio of the tautomers is not determined, we can conclude that the tautomer which dominates the FE-spectra measured at $1.90 \mathrm{eV}$ has a blue-shifted $\mathrm{S}_{0} \rightarrow \mathrm{S}_{2}$ transition as compared to the other tautomer. The FE-spectra measured at $1.90 \mathrm{eV}$ has a much sharper and less asymmetric peak at $2.01 \mathrm{eV}$ than the spectrum measured at $1.75 \mathrm{eV}$. This lead to the conclusion that the tautomer which dominates the spectrum measured at $1.90 \mathrm{eV}$ has a sharper and probably blue-shifted $\mathrm{S}_{0} \rightarrow \mathrm{S}_{1}$ transition. 


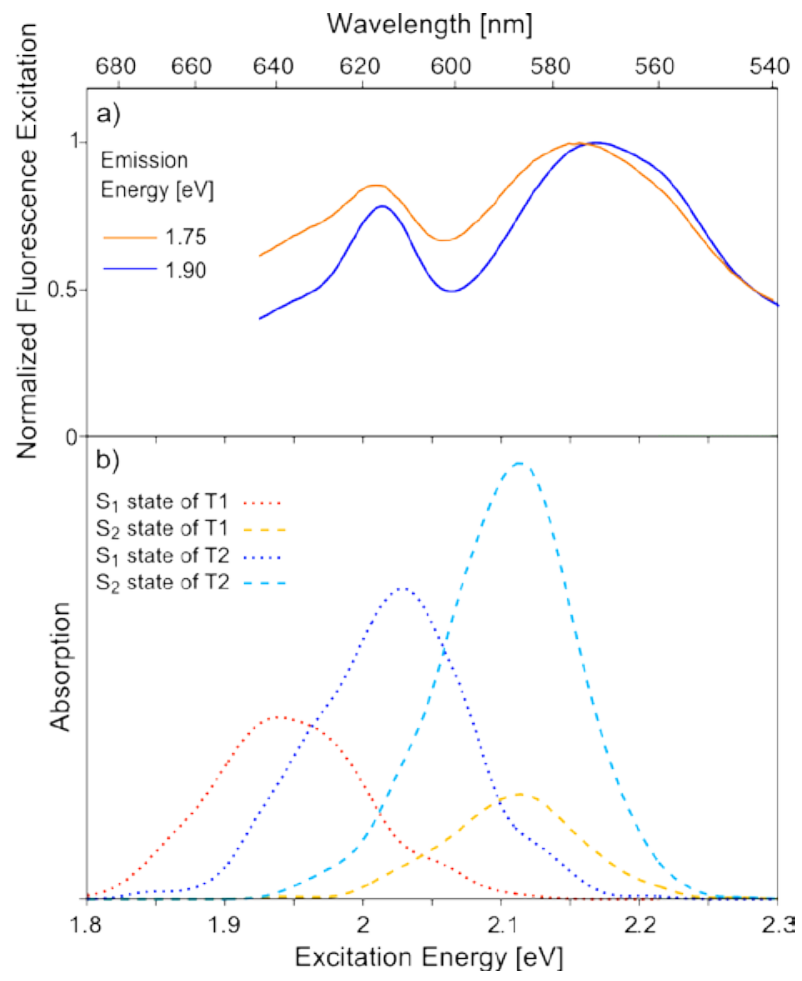

Figure 7: a) Normalized fluorescence excitation (FE, normalized at $2.15 \mathrm{eV}$, corrole concentration: $4.6 \mu \mathrm{mol} / \mathrm{l}$ in chloroform solution) spectra detected at emission wavelengths of 1.75 and $1.90 \mathrm{eV}$. b) Dotted and dashed blue (orange) lines are the vibrationally broadened (VB) absorption spectra of $S_{0} \rightarrow S_{1}$ and $S_{0} \rightarrow S_{2}$ transitions for $T 1$ (T2), respectively. Spectra are calculated for each truncated tautomer (octyl replaced by propyl) from 585 snapshots taken from ab initio molecular dynamics at the $\omega$ PBEh/lanl2dz level of theory using a range-separation parameter of $\omega=0.12 / \mathrm{a}_{\mathrm{B}}$ and a bathochromic shift of $0.365 \mathrm{eV}$. No solvation effects were taken into account for the vibrationally broadened spectra. The $S_{0} \rightarrow S_{1}$ peaks of T1 and T2 are scaled to match the corresponding experimental peaks of the absorption spectra measured in chloroform, while not manipulating the $\mathrm{S}_{1} / \mathrm{S}_{2}$ ratio for both tautomers.

In order to assign T1 and T2 to the experimentally derived spectra, we compared them to quantum chemically calculated spectra of $\mathrm{T} 1$ and $\mathrm{T} 2$, see Figure $7 \mathrm{~b}$. Because of the strong vibrational progression in the Q-band spectral range, we calculated the absorption spectra by means of TDDFT calculations that are based on snapshots of $a b$ initio molecular dynamics trajectories to account for vibrational broadening. The spectrum measured at $1.90 \mathrm{eV}$ is dominated by the tautomer $\mathrm{T} 2$, which can be seen from the sharp $\mathrm{S}_{0} \rightarrow \mathrm{S}_{1}$ transition at $2.01 \mathrm{eV}$. 
Lowering of the detection energy to $1.75 \mathrm{eV}$ leads to an increased contribution of T1 which leads to a significant broadening of the peaks. Thus, we can conclude that the tautomer with protonated $\mathrm{N}(21), \mathrm{N}(22)$ and $\mathrm{N}(23)$ is the red-shifted $\mathrm{T} 1$, while the blue-shifted $\mathrm{T} 2$ has protonated $\mathrm{N}(21), \mathrm{N}(22)$ and $\mathrm{N}(24)$ (see Figure 1), a situation that was found for other mesopyrimidinylcorrole derivatives as well ${ }^{25}$.

\section{CONCLUSIONS}

In the present work, we have investigated the influence of deprotonation and $\mathrm{NH}$ tautomerization on the absorption and fluorescence spectra of an amphiphilic mesopyrimidinylcorrole by different methods. Apart from the quantum-mechanical calculation of the spectra of both $\mathrm{NH}$-tautomers, we used two experimental methods, one based on fluorescence excitation spectra and one based on spectral changes induced by preferential stabilization in solvents of different polarity of the deprotonated and the free-base species, to identify the individual spectral features of the deprotonated and the tautomeric species.

We found that the deprotonated and free-base species differ significantly in their dipole moments. Hence, we conclude that the deprotonated species dominates in propylene carbonate, while the free-base species dominates in all the investigated less polar solvents. Therefore, the absorption spectra differ significantly between propylene carbonate and less polar solutions, whereas specific solvatochromic effects are negligible for the individual freebase corrole species. The absorption features of the individual $\mathrm{NH}$-tautomers in chloroform were assigned by means of $a b$ initio MD calculations to account for the complex vibrational 
broadening and fluorescence excitation spectroscopy. The $S_{0} \rightarrow S_{1}$ absorption of T1 is red-shifted relative to $\mathrm{T} 2$, while the $\mathrm{S}_{0} \rightarrow \mathrm{S}_{2}$-absorptions are at very similar energies for both $\mathrm{NH}$-tautomers.

In the case at hand, where these three species can be transformed into each other when significantly changing the solvent polarity, knowledge of the spectral characteristics of these species is of utmost importance to identify and monitor the dominant species upon formation of supramolecular structures, which will differ depending on the molecular species that dominates. Because of the amphiphilicity of the meso-pyrimidinylcorrole investigated here, supramolecular structures can be formed preferentially at hetero-interfaces between water and air, as in the Langmuir-Blodgett technique, or between two solvents of different polarity, as in the liquid-liquid interface precipitation technique. From the spectroscopic methods presented here, fluorescence excitation spectroscopy might be particularly suited to be applied directly to the molecularly thin layers at LB troughs to monitor changes in the equilibrium between

deprotonated species and free-base $\mathrm{NH}$-tautomers upon variation of the processing parameters, which will be explored in further studies.

\section{ACKNOWLEDGEMENTS}

We are very grateful to Karin Kobow for sample preparation and for the UV-vis measurements and to Torsten Sachse for discussions about the theoretical details of this work. JP and BD acknowledge funding from the Nagelschneider Stiftung. FH and MP acknowledge funding from the German Federal Ministry of Education and Research (Bundesministerium für Bildung und 
Forschung, BMBF, FKZ: 03EK3507). WM acknowledges Hasselt University for continuous

financial support. THN thanks the International Center for Young Scientists (ICYS) for continuing support and JST CREST for the financial support. KA acknowledges JSPS KAKENHI Grant Number JP16H06518 (Coordination Asymmetry) and JST CREST. MK acknowledges the Foundation for Fundamental Research of the Republic of Belarus for financial support. This work was also partly supported by the World Premier International Research Center Initiative (WPI Initiative), MEXT, Japan.

\section{SUPPORTING INFORMATION}

The Supporting Information contains further information on the fitting and decomposition of the fluorescence excitation spectra, as well as a discussion of the calculated molecular orbitals and charge difference densities and the optimized geometries of both tautomers and the deprotonated species.

\section{REFERENCES}

1. Knyukshto, V. N.; Ngo, T. H.; Dehaen, W.; Maes, W.; Kruk, M. M., Phosphorescence of free base corroles. RSC Advances 2016, 6 (50), 43911-43915.

2. $\quad$ Bursa, B.; Wrobel, D.; Barszcz, B.; Kotkowiak, M.; Vakuliuk, O.; Gryko, D. T.; Kolanowski, L.; Baraniak, M.; Lota, G., The impact of solvents on the singlet and triplet states of selected fluorine corroles - absorption, fluorescence, and optoacoustic studies. PCCP 2016, 18 (10), 7216-7228.

3. Stefanelli, M.; Pomarico, G.; Tortora, L.; Nardis, S.; Fronczek, F. R.; McCandless, G. T.; Smith, K. M.; Manowong, M.; Fang, Y.; Chen, P., et al., B-nitro-5,10,15-tritolylcorroles. Inorg. Chem. 2012, 51 (12), 6928-6942.

4. Aviv-Harel, I.; Gross, Z., Coordination chemistry of corroles with focus on main group elements. Coord. Chem. Rev. 2011, 255 (7-8), 717-736.

5. Flamigni, L.; Gryko, D. T., Photoactive corrole-based arrays. Chem. Soc. Rev. 2009, 38 (6), 16351646.

6. Huang, H. C.; Shown, I.; Chang, S. T.; Hsu, H. C.; Du, H. Y.; Kuo, M. C.; Wong, K. T.; Wang, S. F.; Wang, C. H.; Chen, L. C., et al., Pyrolyzed cobalt corrole as a potential non-precious catalyst for fuel cells. Adv. Funct. Mater. 2012, 22 (16), 3500-3508.

7. Levy, N.; Mahammed, A.; Kosa, M.; Major, D. T.; Gross, Z.; Elbaz, L., Metallocorroles as nonprecious-metal catalysts for oxygen reduction. Angew. Chem. Int. Ed. 2015, 54 (47), 14080-14084. 
8. Schöfberger, W.; Faschinger, F.; Chattopadhyay, S.; Bhakta, S.; Mondal, B.; Elemans, J. A. A. W.; Müllegger, S.; Tebi, S.; Koch, R.; Klappenberger, F., et al., A bifunctional electrocatalyst for oxygen evolution and oxygen reduction reactions in water. Angew. Chem. Int. Ed. 2016, 55 (7), 2350-2355.

9. Levy, N.; Mahammed, A.; Friedman, A.; Gavriel, B.; Gross, Z.; Elbaz, L., Metallocorroles as nonprecious metal electrocatalysts for highly efficient oxygen reduction in alkaline media. ChemCatChem 2016, 8 (17), 2832-2837.

10. Teo, R. D.; Hwang, J. Y.; Termini, J.; Gross, Z.; Gray, H. B., Fighting cancer with corroles. Chem. Rev. 2017, 117 (4), 2711-2729.

11. Barata, J. F. B.; Zamarrón, A.; Neves, M. G. P. M. S.; Faustino, M. A. F.; Tomé, A. C.; Cavaleiro, J. A. S.; Röder, B.; Juarranz, Á.; Sanz-Rodríguez, F., Photodynamic effects induced by mesotris(pentafluorophenyl)corrole and its cyclodextrin conjugates on cytoskeletal components of hela cells. European Journal of Medicinal Chemistry 2015, 92, 135-144.

12. Agadjanian, H.; Ma, J.; Rentsendorj, A.; Valluripalli, V.; Hwang, J. Y.; Mahammed, A.; Farkas, D. L.; Gray, H. B.; Gross, Z.; Medina-Kauwe, L. K., Tumor detection and elimination by a targeted gallium corrole. Proceedings of the National Academy of Sciences 2009, 106 (15), 6105-6110.

13. Barbe, J. M.; Canard, G.; Brandes, S.; Guilard, R., Selective chemisorption of carbon monoxide by organic-inorganic hybrid materials incorporating cobalt(iii) corroles as sensing components. Chemistry - $a$ European Journal 2007, 13 (7), 2118-2129.

14. Tortora, L.; Pomarico, G.; Nardis, S.; Martinelli, E.; Catini, A.; D'Amico, A.; Di Natale, C.; Paolesse, R., Supramolecular sensing mechanism of corrole thin films. Sensors and Actuators B-Chemical 2013, 187, 72-77.

15. Santos, C. I. M.; Oliveira, E.; Fernandez-Lodeiro, J.; Barata, J. F. B.; Santos, S. M.; Faustino, M. A. F.; Cavaleiro, J. A. S.; Neves, M.; Lodeiro, C., Corrole and corrole functionalized silica nanoparticles as new metal ion chemosensors: A case of silver satellite nanoparticles formation. Inorg. Chem. 2013, 52 (15), 8564-8572.

16. Fischer, S.; Vestfrid, J.; Mahammed, A.; Herrmann-Westendorf, F.; Schulz, M.; Müller, J.; Kiesewetter, O.; Dietzek, B.; Gross, Z.; Presselt, M., Photometric detection of nitric oxide using a dissolved iron(iii) corrole as a sensitizer. ChemPlusChem 2016, 81 (7), 594-603.

17. Paolesse, R.; Nardis, S.; Monti, D.; Stefanelli, M.; Di Natale, C., Porphyrinoids for chemical sensor applications. Chem. Rev. 2017, 117 (4), 2517-2583.

18. Lai, S.-L.; Wang, L.; Yang, C.; Chan, M.-Y.; Guan, X.; Kwok, C.-C.; Che, C.-M., Gold(iii) corroles for high performance organic solar cells. Adv. Funct. Mater. 2014, 24 (29), 4655-4665.

19. Alemayehu, A. B.; Day, N. U.; Mani, T.; Rudine, A. B.; Thomas, K. E.; Gederaas, O. A.; Vinogradov, S. A.; Wamser, C. C.; Ghosh, A., Gold tris(carboxyphenyl)corroles as multifunctional materials: Room temperature near-ir phosphorescence and applications to photodynamic therapy and dye-sensitized solar cells. ACS Applied Materials \& Interfaces 2016, 8 (29), 18935-18942.

20. Brennan, B. J.; Lam, Y. C.; Kim, P. M.; Zhang, X.; Brudvig, G. W., Photoelectrochemical cells utilizing tunable corroles. ACS Applied Materials \& Interfaces 2015, 7 (29), 16124-16130.

21. Senge, M. O.; Sergeeva, N. N., Metamorphosis of tetrapyrrole macrocycles. Angew. Chem. Int. Ed. 2006, 45 (45), 7492-7495.

22. Ding, T.; Harvey, J. D.; Ziegler, C. J., N-h tautomerization in triaryl corroles. Journal of Porphyrins and Phthalocyanines 2005, 9 (1), 22-27.

23. Kruk, M.; Ngo, T. H.; Savva, V.; Starukhin, A.; Dehaen, W.; Maes, W., Solvent-dependent deprotonation of meso-pyrimidinylcorroles: Absorption and fluorescence studies. J. Phys. Chem. A 2012, 116 (44), 10704-10711.

24. Kruk, M.; Ngo, T. H.; Verstappen, P.; Starukhin, A.; Hofkens, J.; Dehaen, W.; Maes, W., Unraveling the fluorescence features of individual corrole nh tautomers. J. Phys. Chem. A 2012, 116 (44), 1069510703. 
25. Beenken, W.; Presselt, M.; Ngo, T. H.; Dehaen, W.; Maes, W.; Kruk, M., Molecular structures and absorption spectra assignment of corrole nh tautomers. The Journal of Physical Chemistry A 2014, 118 (5), 862-871.

26. Beenken, W.; Maes, W.; Kruk, M.; Martínez, T.; Presselt, M., Origin of the individual basicity of corrole nh-tautomers: A quantum chemical study on molecular structure and dynamics, kinetics, and thermodynamics. The Journal of Physical Chemistry A 2015, 119 (26), 6875-6883.

27. Ivanova, Y. B.; Savva, V. A.; Mamardashvili, N. Z.; Starukhin, A. S.; Ngo, T. H.; Dehaen, W.; Maes, W.; Kruk, M. M., Corrole nh tautomers: Spectral features and individual protonation. J. Phys. Chem. A 2012, 116 (44), 10683-10694.

28. Ariga, K.; Yuki, H.; Kikuchi, J.-i.; Dannemuller, O.; Albrecht-Gary, A.-M.; Nakatani, Y.; Ourisson, G., Monolayer studies of single-chain polyprenyl phosphates. Langmuir 2005, 21 (10), 4578-4583.

29. Jin, J.; Li, L. S.; Li, Y.; Zhang, Y. J.; Chen, X.; Wang, D.; Jiang, S.; Li, T. J.; Gan, L. B.; Huang, C. H., Structural characterizations of c60-derivative langmuir-blodgett films and their photovoltaic behaviors. Langmuir 1999, 15 (13), 4565-4569.

30. Modlińska, A.; Piosik, E.; Paluszkiewicz, J.; Martyński, T., Aggregation properties of tetrachloroperylene-tetracarboxylic acid in binary langmuir and langmuir-blodgett films. J. Lumin. 2014, 148, 44-54.

31. Angelova, A.; lonov, R., Monolayer and spectroscopic studies of an amphiphilic (phenylethynyl)anthracene probe in pure and mixed films with charged and neutral lipids. Langmuir 1999, 15 (21), 7199-7207.

32. Modlińska, A.; Bauman, D., The langmuir-blodgett technique as a tool for homeotropic alignment of fluorinated liquid crystals mixed with arachidic acid. International Journal of Molecular Sciences 2011, $12(8), 4923$.

33. Das, S.; Herrmann-Westendorf, F.; Schacher, F. H.; Täuscher, E.; Ritter, U.; Dietzek, B.; Presselt, M., Controlling electronic transitions in fullerene van der waals aggregates via supramolecular assembly. ACS Appl Mater Interfaces 2016, 8 (33), 21512-21.

34. Sathish, M.; Miyazawa, K. i., Size-tunable hexagonal fullerene (c60) nanosheets at the liquid-liquid interface. J. Am. Chem. Soc. 2007, 129 (45), 13816-13817.

35. Das, S. K.; Plentz, J.; Brückner, U.; von der Lühe, M.; Eckhard, O.; Schacher, F. H.; Täuscher, E.; Ritter, U.; Andrä, G.; Dietzek, B., et al., Optoelectronic attributes of fullerene nano-morphology templates: Impact on open circuit voltage. to be submitted 2017.

36. Maes, W.; Ngo, T. H.; Vanderhaeghen, J.; Dehaen, W., Meso-pyrimidinyl-substituted a(2)bcorroles. Org. Lett. 2007, 9 (16), 3165-3168.

37. Ngo, T. H.; Van Rossom, W.; Dehaen, W.; Maes, W., Reductive demetallation of cu-corroles-a new protective strategy towards functional free-base corroles. Organic \& Biomolecular Chemistry 2009, 7 (3), 439-443.

38. Ngo, T. H.; Nastasi, F.; Puntoriero, F.; Campagna, S.; Dehaen, W.; Maes, W., Meso-pyrimidinylsubstituted a(2)b- and a(3)-corroles. J. Org. Chem. 2010, 75 (6), 2127-2130.

39. Ngo, T. H.; Puntoriero, F.; Nastasi, F.; Robeyns, K.; Van Meervelt, L.; Campagna, S.; Dehaen, W.; Maes, W., Synthetic, structural, and photophysical exploration of meso-pyrimidinyl-substituted ab(2)corroles. Chemistry-a European Journal 2010, 16 (19), 5691-5705.

40. Ngo, T. H.; Nastasi, F.; Puntoriero, F.; Campagna, S.; Dehaen, W.; Maes, W., Corrole-porphyrin conjugates with interchangeable metal centers. Eur. J. Org. Chem. 2012, (28), 5605-5617.

41. Rohrdanz, M. A.; Martins, K. M.; Herbert, J. M., A long-range-corrected density functional that performs well for both ground-state properties and time-dependent density functional theory excitation energies, including charge-transfer excited states. The Journal of Chemical Physics 2009, 130 (5), 054112. 42. Wadt, W. R.; Hay, P. J., Ab initio effective core potentials for molecular calculations. Potentials for main group elements na to bi. The Journal of Chemical Physics 1985, 82 (1), 284-298. 
43. Körzdörfer, T.; Brédas, J.-L., Organic electronic materials: Recent advances in the dft description of the ground and excited states using tuned range-separated hybrid functionals. Acc. Chem. Res. 2014, 47 (11), 3284-3291.

44. Refaely-Abramson, S.; Baer, R.; Kronik, L., Fundamental and excitation gaps in molecules of relevance for organic photovoltaics from an optimally tuned range-separated hybrid functional. Physical Review B 2011, 84 (7), 075144.

45. Sachse, T.; Martínez, T. J.; Dietzek, B.; Presselt, M., On combining the conductor-like screening model and optimally-tuned range-separated hybrid density functionals. Journal of Chemical Theory and Computation to be submitted.

46. Sachse, T. Firedeamon. https://github.com/razziel89/FireDeamon.

47. Körzdörfer, T.; Parrish, R. M.; Marom, N.; Sears, J. S.; Sherrill, C. D.; Brédas, J. L., Assessment of the performance of tuned range-separated hybrid density functionals in predicting accurate quasiparticle spectra. Physical Review B 2012, 86 (20), 205110.

48. Pandey, L.; Doiron, C.; Sears, J. S.; Bredas, J. L., Lowest excited states and optical absorption spectra of donor-acceptor copolymers for organic photovoltaics: A new picture emerging from tuned long-range corrected density functionals. Phys. Chem. Chem. Phys. 2012, 14, 14243.

49. Isborn, C. M.; Luehr, N.; Ufimtsev, I. S.; Martínez, T. J., Excited-state electronic structure with configuration interaction singles and tamm-dancoff time-dependent density functional theory on graphical processing units. Journal of Chemical Theory and Computation 2011, 7 (6), 1814-1823.

50. Bergsma, J. P.; Berens, P. H.; Wilson, K. R.; Fredkin, D. R.; Heller, E. J., Electronic spectra from molecular dynamics: A simple approach. The Journal of Physical Chemistry 1984, 88 (3), 612-619.

51. Crespo-Otero, R.; Barbatti, M., Spectrum simulation and decomposition with nuclear ensemble: Formal derivation and application to benzene, furan and 2-phenylfuran. Theor. Chem. Acc. 2012, 131 (6), 1-14.

52. Isborn, C. M.; Götz, A. W.; Clark, M. A.; Walker, R. C.; Martínez, T. J., Electronic absorption spectra from $\mathrm{mm}$ and ab initio $\mathrm{qm} / \mathrm{mm}$ molecular dynamics: Environmental effects on the absorption spectrum of photoactive yellow protein. Journal of Chemical Theory and Computation 2012, 8 (12), 50925106.

53. Kruithof, N. 3d skin surface meshing, CGAL Editorial Board: 2015.

54. Flores-Moreno, R.; Alvarez-Mendez, R. J.; Vela, A.; Köster, A. M., Half-numerical evaluation of pseudopotential integrals. J. Comput. Chem. 2006, 27 (9), 1009-1019.

55. Abrahams, D.; Gurtovoy, A., C++ template metaprogramming: Concepts, tools, and techniques from boost and beyond. Addison-Wesley: 2005.

56. Beazley, D. M., Swig: An easy to use tool for integrating scripting languages with $\mathrm{c}$ and $\mathrm{c}++$. . In Proceedings of the 4th conference on USENIX Tcl/Tk Workshop, 1996 - Volume 4, USENIX Association: Monterey, California, 1996; pp 15-15.

57. Ltd., P. o. V. P. Persistence of vision (tm) raytracer, Williamstown, Victoria, Australia, 2004. 58. Presselt, M.; Schnedermann, C.; Schmitt, M.; Popp, J., Prediction of electron densities, the respective laplacians and ellipticities in bond-critical points of phenyl-ch-bonds via linear relations to parameters of inherently localized cd stretching vibrations and 1h-nmr-shifts. J. Phys. Chem. A 2009, 113 (13), 3210-3222.

59. $\quad$ Presselt, M.; Dietzek, B.; Schmitt, M.; Rau, S.; Winter, A.; Jäger, M.; Schubert, U. S.; Popp, J., A concept to tailor electron delocalization: Applying qtaim analysis to phenyl-terpyridine compounds. $J$. Phys. Chem. A 2010, 114 (50), 13163-13174.

60. Presselt, M.; Schnedermann, C.; Müller, M.; Schmitt, M.; Popp, J., Derivation of correlation functions to predict bond properties of phenyl-ch bonds based on vibrational and h-1 nmr spectroscopic quantities. J. Phys. Chem. A 2010, 114 (37), 10287-10296. 
61. Presselt, M.; Wojdyr, M.; Beenken, W. J. D.; Kruk, M.; Martínez, T. J., Steric and electronic contributions to the core reactivity of monoprotonated 5-phenylporphyrin: A dft study. Chem. Phys. Lett. 2014, 603 (0), 21-27.

62. Presselt, M.; Dehaen, W.; Maes, W.; Klamt, A.; Martínez, T.; Beenken, W. J. D.; Kruk, M., Quantum chemical insights into the dependence of porphyrin basicity on the meso-aryl substituents: Thermodynamics, buckling, reaction sites and molecular flexibility. PCCP 2015, 17 (21), 14096-14106. 63. Habenicht, S. H.; Schramm, S.; Fischer, S.; Sachse, T.; Herrmann-Westendorf, F.; Bellmann, A.; Dietzek, B.; Presselt, M.; Weiß, D.; Beckert, R., et al., Tuning the polarity and surface activity of hydroxythiazoles - extending the applicability of highly fluorescent self-assembling chromophores to supra-molecular photonic structures. Journal of Materials Chemistry C 2016, 4 (5), 958-971.

64. Klamt, A.; Schuurmann, G., Cosmo - a new approach to dielectric screening in solvents with explicit expressions for the screening energy and its gradient. Journal of the Chemical Society-Perkin Transactions 2 1993, (5), 799-805.

65. Eckert, F.; Klamt, A., Accurate prediction of basicity in aqueous solution with cosmo-rs. J. Comput. Chem. 2006, 27 (1), 11-19.

66. Hansch, C.; Leo, A.; Taft, R. W., A survey of hammett substituent coonstants and resonance and field parameters. Chem. Rev. 1991, 91, 165-195.

67. Hammett, L. P., The effect of structure upon the reactions of organic compounds.

Benzene derivatives. Physical Organic Chemistry 1940, 59, 96-103.

68. Swain, C. G.; Swain, M. S.; Powell, A. L.; Alunni, S., Solvent effects on chemical reactivity. Evaluation of anion- and cation-solvation components. J. Am. Chem. Soc. 1983, 105 (3), 502-513. 69. Jaffe, H. H., A reexamination of the hammett equation. Chem. Rev. 1953, 53 (191), 191-261.

70. Kamlet, M. J.; Abboud, J. L. M.; Taft, R. W., An examination of linear solvation energy relationships. In Progress in physical organic chemistry, John Wiley \& Sons, Inc.: 2007; pp 485-630.

71. Beenken, W. J. D.; Herrmann, F.; Presselt, M.; Hoppe, H.; Shokhovets, S.; Gobsch, G.; Runge, E., Sub-bandgap absorption in organic solar cells: Experiment and theory. PCCP 2013, 15 (39), 16494-16502.

72. Preiß, J.; Jäger, M.; Rau, S.; Dietzek, B.; Popp, J.; Martínez, T.; Presselt, M., How does peripheral functionalization of ruthenium(ii)-terpyridine complexes affect spatial charge redistribution after photoexcitation at the franck-condon point? ChemPhysChem 2015, 16 (7), 1395-1404.

73. Gampe, D. M.; Kaufmann, M.; Jakobi, D.; Sachse, T.; Presselt, M.; Beckert, R.; Görls, H., Stable and easily accessible functional dyes: Dihydrotetraazaanthracenes as versatile precursors for higher acenes. Chemistry - A European Journal 2015, 21 (20), 7571-7581.

74. Liu, F.; Luehr, N.; Kulik, H. J.; Martínez, T. J., Quantum chemistry for solvated molecules on graphical processing units using polarizable continuum models. Journal of Chemical Theory and Computation 2015, 11 (7), 3131-3144. 
TOC GRAPHIC

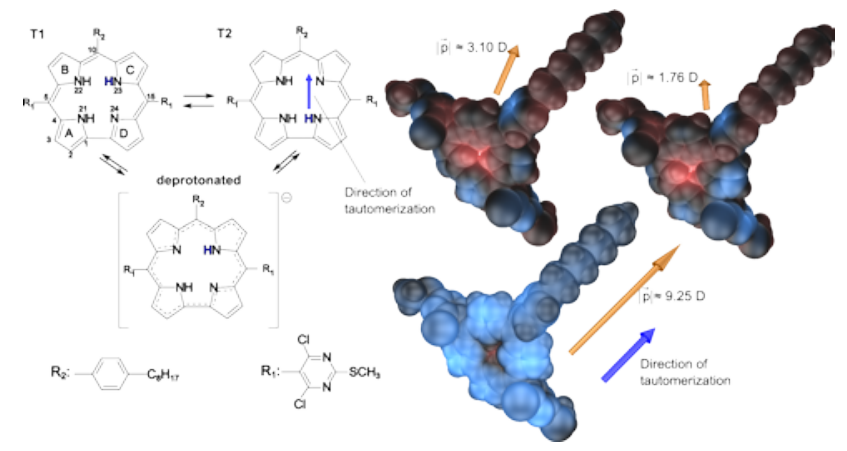

TOC Graphic

31 